Subscriber access provided by University of Manitoba Libraries

Agricultural and Environmental Chemistry

\title{
Development of novel microparticles for effective delivery of thymol and lauric acid to pig intestinal tract
}

Faith A Omonijo, Seung II Kim, Tracy Guo, Qi Wang, Joshua Gong, Ludovic Lahaye, Jean-Christophe Bodin, Martin Nyachoti, Song Liu, and Chengbo Yang

J. Agric. Food Chem., Just Accepted Manuscript • DOI: 10.1021/acs.jafc.8b02808 • Publication Date (Web): 24 Aug 2018

Downloaded from http://pubs.acs.org on August 27, 2018

\section{Just Accepted}

"Just Accepted" manuscripts have been peer-reviewed and accepted for publication. They are posted online prior to technical editing, formatting for publication and author proofing. The American Chemical Society provides "Just Accepted" as a service to the research community to expedite the dissemination of scientific material as soon as possible after acceptance. "Just Accepted" manuscripts appear in full in PDF format accompanied by an HTML abstract. "Just Accepted" manuscripts have been fully peer reviewed, but should not be considered the official version of record. They are citable by the Digital Object Identifier (DOI®). "Just Accepted" is an optional service offered to authors. Therefore, the "Just Accepted" Web site may not include all articles that will be published in the journal. After a manuscript is technically edited and formatted, it will be removed from the "Just Accepted" Web site and published as an ASAP article. Note that technical editing may introduce minor changes to the manuscript text and/or graphics which could affect content, and all legal disclaimers and ethical guidelines that apply to the journal pertain. ACS cannot be held responsible for errors or consequences arising from the use of information contained in these "Just Accepted" manuscripts. 


\section{Running title: Microencapsulated essential oils and fatty acids for feed application}

Title: Development of novel microparticles for effective delivery of thymol and lauric acid to pig intestinal tract

5

Faith A. Omonijo ${ }^{1}$, Seungil Kim ${ }^{2}$, Tracy Guo ${ }^{4}$, Qi Wang ${ }^{4}$, Joshua Gong ${ }^{4}$, Ludovic Lahaye ${ }^{5}$,

7 Jean-Christophe Bodin ${ }^{5}$, Martin Nyachoti ${ }^{1}$, Song Liu ${ }^{2,3}$, and Chengbo Yang ${ }^{1 *}$

$8{ }^{1}$ Department of Animal Science, University of Manitoba, Winnipeg, MB, Canada R3T 2N2;

$9 \quad{ }^{2}$ Biomedical Engineering, University of Manitoba, Winnipeg, MB, Canada R3T 2N2;

$10{ }^{3}$ Department of Biosystems Engineering, University of Manitoba, Winnipeg, MB, Canada R3T

11 2N2; ${ }^{4}$ Guelph Research and Development Centre, Agriculture and Agri-Food Canada, 93 Stone

12 Road West, Guelph, ON, Canada N1G 5C9; '5efo Nutrition Inc., Saint-Hyacinthe, Quebec,

13 Canada J2S $7 B 6$

14

$15 *$ Corresponding author: Chengbo Yang, Ph.D., Assistant Professor

16 Livestock Nutrition/Nutritional Biochemistry

17 Department of Animal Science

18 University of Manitoba, Winnipeg, MB, R3T 2N2

19 Tel: $+1.204 .474 .8188 \mid$ Fax: +1.204 .474 .7628$

20 Email: Chengbo.Yang@umanitoba.ca 


\section{ABSTRACT}

23 Antibiotics have been widely supplemented in feeds at sub-therapeutic concentrations to prevent

24 post-weaning diarrhea and increase the overall productivity of pigs. However, the emergence of

25 antimicrobial-resistant bacteria worldwide has made it urgent to minimize the use of in-feed

26 antibiotics. The development of promising alternatives to in-feed antibiotics is crucial for

27 maintaining the suitability of swine production. Both medium-chain fatty acids (MCFA) and

28 essential oils exhibit great potential to post-weaning diarrhea; however; their direct inclusion has

29 compromised efficacy because of several factors including low stability, poor palatability and

30 low availability in the lower gut. Therefore, the objective of this study was to develop a

31 formulation of microparticles to deliver a model of essential oil (thymol) and MCFA (lauric

32 acid). The composite microparticles were produced by the incorporation of starch and alginate

33 through a melt-granulation process. The release of thymol and lauric acid from the microparticles

34 was in vitro determined using simulated salivary fluid (SSF), simulated gastric fluid (SGF) and

35 simulated intestinal fluid (SIF), consecutively. The microparticles prepared with $2 \%$ alginate

36 solution displayed a slow release of thymol and lauric acid in the SSF $(21.2 \pm 2.3 \% ; 36 \pm 1.1 \%)$,

37 SGF $(73.7 \pm 6.9 \% ; 54.8 \pm 1.7 \%)$ and SIF $(99.1 \pm 1.2 \% ; 99.1 \pm 0.6 \%)$, respectively, whereas, the

38 microparticles without alginate showed a rapid release of thymol and lauric acid from the SSF

$39 \quad(79.9 \pm 11.8 \% ; 84.9 \pm 9.4 \%)$, SGF $(92.5 \pm 3.5 \% ; 75.8 \pm 5.9 \%)$ and SIF $(93.3 \pm 9.4 \% ; 93.3 \pm$

$404.6 \%$ ), respectively. The thymol and lauric acid in the developed microparticles with or without

41 alginate both exhibited excellent stabilities ( $>90 \%$ ) during being stored at $4^{\circ} \mathrm{C}$ for 12 weeks and

42 after being stored at room temperature for 2 weeks. These results evidenced that the approach

43 developed in the present study could be potentially employed to deliver thymol and lauric acid to 
44 the lower gut of pigs, although, further in vivo investigations are necessary to validate the 45 efficacy of the microparticles.

46 Keywords: Encapsulation; Gut, Lauric acid, Microparticles, Slow release, Thymol

\section{1. INTRODUCTION}

48 Young animals are very vulnerable to diseases, and using antimicrobials is the most cost49 effective method to improve the health and productivity of food production animals raised with 50 conventional agricultural techniques (Looft et al., 2012; Yang et al., 2015). Although this 51 practice has been banned in Europe and other countries have also started to minimize the use of 52 antibiotics in the animal production, it still exists in major parts of the world (Hassan et al., 53 2018). Therefore, replacing antibiotics with cost-effective alternatives remains crucial to ensure a 54 sustainable food animal production.

55 Essential oils are considered as valid candidates to replace antibiotics in the feed industry (Li et 56 al., 2012; Gong et al., 2014; Omonijo et al., 2018). Essential oils (e.g., thymol) are extracted 57 from plants and can promote growth performance and health in animals because of their 58 biological activities and antimicrobial activities (Si et al. 2006a; Edris, 2007; Del Nobile et al. 59 2008; Brenes et al., 2010; Puvaca et al., 2013; Rassu et al, 2014). With the identification and 60 characterization of bioactive components in plant extracts and significant progress in mechanistic 61 research with these components in food production animals, many research efforts have been 62 made to use essential oils substituting antibiotics within the animal production chain (Omonijo et 63 al., 2018). The rationales for using essential oils in animal feeds have relied on their abilities to 64 inhibit bacterial growth, reduce virulence through quorum-sensing disruption, and regulate innate 65 immunity of animals (Hassan et al., 2018). However, most essential oils have a high minimum 66 inhibitory concentration (MIC) that are unlikely accepted in the industry regarding cost- 
67 efficiency, feed palatability and government regulation (Yang et al., 2015; Omonijo et al., 2018;

68 Hassan et al., 2018). Therefore, it is vital to ensure the delivery of essential oils to the target site

69 for increasing their efficacy.

70 Essential oils have very high volatility, and their bioactive compounds are readily degradable

71 when exposed to heat, oxygen, light, or during their interactions with other compounds, thus,

72 negatively affecting their biological activities and antimicrobial activities (Si et al., 2006a ;

73 Zhang et al., 2016a; Gonçalves et al., 2017). Additionally, several studies are demonstrating that

74 several essential oils including thymol and carvacrol have almost completely vanished in the

75 upper digestive tract of pigs (Michiels et al., 2008; Zhang et al., 2016a). Therefore, unprotected

76 essential oils can be significantly vanished at the manufacture, transportation, and storage of

77 feeds and as well as during delivery to the pig gut, thus hindering access to the distal part of pig 78 intestine (Omonijo et al., 2018). This serves as a major challenge to the use of essential oil in pig 79 feeds. Thus, it is crucial to establish a useful and practical delivery approach for using essential 80 oils in feeds.

81 Medium-chain fatty acids (MCFA) including lauric acid $\left(\mathrm{C}_{12}\right)$ and its ester derivatives also have 82 potential to substitute antibiotics in weaning piglets (Han et al., 2011; Zentek et al., 2012; 2013;

83 Hanczakowska et al., 2013; De Smet et al., 2016). Several studies indicated that MCFA could 84 inhibit Salmonella growth (Van Immerseel et al., 2004; Messens et al., 2010). Synergistic 85 antimicrobial activities between oregano oil and caprylic acid were observed with several strains 86 including Salmonella (Hulánková and Bořilová, 2011). Similarly, Vande Maele et al. (2016) 87 demonstrated in an in vitro study that a combination of lauric acid and cinnamaldehyde had 88 synergistic effects in inhibiting the growth of Brachyspira hyodysenteriae that causes swine 89 dysentery. The use of MCFA is popular both in the food and feed industries. However, some 
MCFA and their ester derivatives can compromise feed palatability and acceptance and reduce

91 feed intake in pigs due to their unpleasant odors (Omonijo et al., 2018). Thus, it is also essential

92 to develop a useful and practical delivery approach for using MCFA in feeds.

93 Microencapsulation has been becoming one of the most popular and practical approaches to 94 mask the unpleasant taste/odor, and deliver bioactive compounds in food production animals 95 (Piva et al., 2007; Chitprasert et al., 2014). Ideal microencapsulation should not only stabilize essential oils but also release them specifically in the targeted regions of the intestine (Chen et

97 al., 2017; Omonijo et al., 2018). Therefore, the objective of the present study was to develop a 98 formulation of microparticles containing both thymol and MCFA for effective delivery to pig 99 intestinal tract.

\section{MATERIALS AND METHODS}

101

\subsection{Materials}

102 Thymol ( $\geq 98.5 \%$ ), lauric acid (LA), palmitic acid (PA, $\left.\mathrm{C}_{16}\right)$, stearic acid (SA, $\left.\mathrm{C}_{18}\right)$, amylase, 103 sodium alginate (low viscosity), pepsin originated from porcine and pancreatin originated from 104 porcine were purchased from Sigma-Aldrich (Oakville, Ontario, Canada). Cornstarch was 105 purchased from Cargill (Cargill Inc., Minneapolis, MN, USA) and pre-gelatinized starch (1500) 106 from Coloran (West Point, PA, USA).

107

108

109

\subsection{Selection of a suitable fatty acid}

Three fatty acids including lauric acid, palmitic acid, and stearic acid were used in this experiment because those have a melting point above a melting point $\left(42^{\circ} \mathrm{C}\right)$ of thymol and have been used to deliver bioactive compounds (Ma et al., 2016; Pitigraisorn et al., 2017). The melting points of lauric acid, palmitic acid, and stearic acid are $43^{\circ} \mathrm{C}, 63^{\circ} \mathrm{C}$ and $69^{\circ} \mathrm{C}$, respectively. Ten grams of each fatty acid was mixed with $10 \mathrm{~g}$ of thymol, respectively. The mixtures were then 
113 melted in a water bath at $70^{\circ} \mathrm{C}$. After melting, the mixtures were stirred for $30 \mathrm{~min}$. The molten

114 mixture of each fatty acid with thymol was left to stay at $55^{\circ} \mathrm{C}$ without stirring for $2 \mathrm{~h}$ before

115 placing at room temperature $\left(23^{\circ} \mathrm{C}\right)$ up to $6 \mathrm{~h}$ to allow for solidification.

116 To observe the crystal morphology of thymol, lauric acid, and their mixture, an emulsion of

117 thymol, lauric acid and the mixture of thymol and lauric acid (ratio 1:1) were prepared. Lauric

118 acid and thymol were melted at $70^{\circ} \mathrm{C}$ individually or mixed at a ratio of $1: 1$, and then added into

119 the water at $10 \%$ with $1 \%$ tween 80 as a surfactant. The mixture was mixed using a Polytron

120 (PT10-35GT, Kinematica AG, Switzerland) for $2 \mathrm{~min}$ at 13,000 rpm to make an emulsion. Then,

121 three emulsions were stored at $4^{\circ} \mathrm{C}$ overnight allowing the emulsions to crystallize. The crystal

122 morphology was examined under a microscope (Eclipse Ci, Nikon, Japan).

123

124 2.3. The melting point of thymol, lauric acid, and their mixture

125 Among the three fatty acids tested, lauric acid was selected for further study because its mixture 126 with thymol remained a homogeneous liquid at room temperature for $6 \mathrm{~h}$. Before use, $1 \mathrm{~g}$ of 127 thymol and lauric acid each were kept at $-80^{\circ} \mathrm{C}$ for $30 \mathrm{~min}$ and then mixed by vortexing for 30 $128 \mathrm{sec}$ at 3,000 rpm. The mixture was kept in $-80^{\circ} \mathrm{C}$ for $3 \mathrm{~h}$ and then ground to a fine powder using a 129 grinder. The grinder was kept $-20^{\circ} \mathrm{C}$ for $3 \mathrm{~h}$ before use to avoid increasing temperature to higher 130 than the melting temperature of thymol and lauric acid. The melting temperature of the thymol, 131 lauric acid, and their mixture (50:50 $\mathrm{wt} \%$ ) was measured by differential scanning calorimetry 132 (DSC). For the measurement, $12.1 \mathrm{mg}$ thymol, $13.1 \mathrm{mg}$ lauric acid, and $10.7 \mathrm{mg}$ mixture were 133 weighed into individual Tzero Aluminum hermetic pans. The pan was placed in the chamber of 134 DSC (Q Series DSC, TA Instrument). The DSC was programmed as follow: 1) Equilibrate at 
$13525^{\circ} \mathrm{C}$; 2) Jump to $-10^{\circ} \mathrm{C}$; 3) Ramp $10^{\circ} \mathrm{C} / \mathrm{min}$ to $80^{\circ} \mathrm{C}$ (1st run); 4) Cooling; 5) Equilibrate at $13610^{\circ} \mathrm{C}$; 6) Isothermal for $5 \mathrm{~min}$; and 7) Ramp $10^{\circ} \mathrm{C} / \mathrm{min}$ to $80^{\circ} \mathrm{C}$ (2nd run).

\section{2.4. Preparation of microparticles}

138 For preparing microparticles without adding $2 \%$ alginate solution, $5 \mathrm{~g}$ of lauric acid and $5 \mathrm{~g}$ of 139 thymol were weighed into a closed vial separately and melted at $70^{\circ} \mathrm{C}$ in a water bath, mixed 140 together and stirred for $30 \mathrm{~min}$. Thirty grams of cornstarch and $5 \mathrm{~g}$ of pre-gelatinized starch (a 141 ratio of 6:1) were weighed separately and then mixed in a container by hand shaking. The molten 142 thymol and lauric acid mixture was added into the starch mixture and then mixed by hand 143 stirring. Fifteen milliliters of distilled water (3 times of pre-gelatinized starch) was added to the 144 mixture. The containers were immediately placed into an ice-water bath for $1.5 \mathrm{~h}$ and kept in a 145 refrigerator $\left(4^{\circ} \mathrm{C}\right)$ overnight for solidification. The solid particles were then granulated into 146 micro-particles with a granulating machine (UAM Pharmag, Germany) at $90 \mathrm{rpm}$ using a pore 147 size of $0.1 \mathrm{~mm}$ and dried at room temperature $\left(23^{\circ} \mathrm{C}\right)$ for $1 \mathrm{~h}$ before being stored in a refrigerator $148 \quad\left(4^{\circ} \mathrm{C}\right)$.

149 For preparing microparticles with alginate, a total of $0.3 \mathrm{~g}$ of alginate was weighed and dissolved 150 in $15 \mathrm{~mL}$ of distilled water to make a $2 \%(\mathrm{w} / \mathrm{v})$ alginate solution. The same protocol described 151 above was used to make the microparticles except for replacing the $15 \mathrm{~mL}$ of water with the $2 \%$ 152 alginate solution.

\section{2.5. Morphology of microparticles}

155 The morphology of the microparticles produced with or without adding a $2 \%$ alginate solution 156 was determined with a light microscope (Axio Cam 105, Carl-Zeiss, Switzerland; Nikon eclipse, 
157 Japan) at $10 \times$ magnification and the Zen Image Software (2012) was used to determine the 158 surface diagram of the microparticles.

159

160

161

162

163

164

165

166

167

168

169

170

171

172

173

174

175

176

177

178

179

\subsection{In vitro release of thymol and lauric acid from the microparticles}

In vitro release of thymol and lauric acid from the microparticles was determined with simulated digestive fluid using previously published procedures with some modifications (Minekus et al. 2014). The simulated salivary fluid (SSF) contained $15.1 \mathrm{mmol} / \mathrm{L} \mathrm{KCl}, 13.6 \mathrm{mmol} / \mathrm{L} \mathrm{NaHCO}_{3}$, $3.7 \mathrm{mmol} / \mathrm{L} \mathrm{KH}_{2} \mathrm{PO}_{4}, 0.15 \mathrm{mmol} / \mathrm{L} \mathrm{MgCl}_{2}\left(\mathrm{H}_{2} \mathrm{O}\right)_{6}$ and $0.06 \mathrm{mmol} / \mathrm{L}\left(\mathrm{NH}_{4}\right)_{2} \mathrm{CO}_{3}$. The simulated gastric fluid (SGF) contained $47.2 \mathrm{mmol} / \mathrm{L} \mathrm{NaCl}, 25 \mathrm{mmol} / \mathrm{L} \mathrm{NaHCO} 3,6.9 \mathrm{mmol} / \mathrm{L} \mathrm{KCl}, 0.9$ $\mathrm{mmol} / \mathrm{L} \mathrm{KH}_{2} \mathrm{PO}_{4}, 0.5 \mathrm{mmol} / \mathrm{L}\left(\mathrm{NH}_{4}\right)_{2} \mathrm{CO}_{3}$ and $0.1 \mathrm{mmol} / \mathrm{L} \mathrm{MgCl}_{2}\left(\mathrm{H}_{2} \mathrm{O}\right)_{6}$. The simulated intestinal fluid (SIF) contained $85 \mathrm{mmol} / \mathrm{L} \mathrm{NaHCO}_{3}, 38.4 \mathrm{mmol} / \mathrm{L} \mathrm{NaCl}, 6.8 \mathrm{mmol} / \mathrm{L} \mathrm{KCl}, 0.8$ $\mathrm{mmol} / \mathrm{L} \mathrm{KH}_{2} \mathrm{PO}_{4}$ and $0.33 \mathrm{mmol} / \mathrm{L} \mathrm{MgCl}_{2}\left(\mathrm{H}_{2} \mathrm{O}\right)_{6}$. The $\mathrm{pH}$ of SSF, SGF and SIF was adjusted using $\mathrm{HCl}$ or $\mathrm{NaOH}$ to $7.0,3.0$ and 7.0, respectively. The final digestion mixtures of the electrolyte solution for SSF, SGF and SIF contained 1.5, 0.15 and $0.6 \mathrm{mmol} / \mathrm{L}$ of $\mathrm{CaCl}_{2}\left(\mathrm{H}_{2} \mathrm{O}\right)_{2}$, respectively. Respective enzymes were also added to simulate digestion in pig digesta. Alphaamylase originated from human saliva was included in the SSF final digestion mixture at a concentration of $75 \mathrm{U} / \mathrm{mL}$. Pepsin originated from porcine gastric mucosa was added to the SGF final digestion mixture at a concentration of $2000 \mathrm{U} / \mathrm{mL}$ and pancreatin originated from porcine pancreas was added to the SIF final digestion mixture at a concentration of $100 \mathrm{U} / \mathrm{mL}$.

Forty microparticle samples (each $0.5 \mathrm{~g}$ ) were employed to mimic digestion within the mouth, stomach and small intestine in pigs. Four samples were taken from each sampling point $(0,2,30$, $60,90,120,150,180,210$ and $240 \mathrm{~min}$ ) with points between 0 to 2 min representing the digestion in the mouth, 2 to 120 in the stomach and 120 to $240 \mathrm{~min}$ in the small intestine. All simulated solutions were maintained at $37^{\circ} \mathrm{C}$. The SSF was added to each of the samples at a 
180 ratio of $1: 1$ and placed in the incubator with shaking (Innova TM. 4200, New Brunswick 181 Scientific, Edison/ NJ. USA) for $2 \mathrm{~min}$. The $\mathrm{pH}$ was adjusted to 3 with $1 \mathrm{M} \mathrm{HCl}$ before SGF was 182 added. At the end of the SGF stage, the $\mathrm{pH}$ was adjusted to 7 with $1 \mathrm{M} \mathrm{NaOH}$ followed by 183 addition of the SIF. To measure the concentration of thymol and lauric acid, $5 \mathrm{~mL}$ of oil 184 extraction solvent (hexane) was added to each of the supernatants, shaken (IKA Vibrax VXR 185 Basic, U.S.A) for $20 \mathrm{~min}$ and allowed to stay for $30 \mathrm{~min}$. Each of the supernatant from each point 186 was diluted 10 times and the diluent was filtrated using a syringe-driven filter unit 187 (polyetrafluoroethylene, $0.22 \mathrm{~nm}$ ) and further analyzed by gas chromatography (GC) following 188 the method explained below. Two replicates for each sample were used.

189 The column installed was SUPELCO $\mathrm{WAX}^{\mathrm{TM}} 10$ (fused silica capillary column; $60 \mathrm{~m} \times 0.25$ $190 \mathrm{~mm} \times 0.50 \mathrm{~nm}$ film thickness and the temperature limits from $\left.35-280^{\circ} \mathrm{C}\right)$. Thymol and lauric acid 191 were identified by comparing the retention time with the standard thymol and lauric acid and 192 their concentrations were calculated by comparing the total peak area of thymol and lauric acid 193 with the standard curve. Released thymol or lauric acid content $=$ thymol or lauric acid 194 concentration in GC vial $\times 5$ (volume of added hexane) $\times$ dilution times/thymol or lauric acid in 195 the dry samples $\times 100 \%$.

\subsection{Determining the stability of thymol and lauric acid in the microparticles}

197 The stability of thymol and lauric acid in the microparticles with or without alginate was 198 measured after being stored at room temperature $\left(23^{\circ} \mathrm{C}\right)$ for 2 weeks and during the storage at $1994{ }^{\circ} \mathrm{C}$ for 12 weeks. The recovery rate of thymol and lauric acid were determined with the 200 procedure described as below. Samples were taken at different time points (1 week, 3 weeks, 6 201 weeks and 12 weeks) for analysis. Each sample $(0.5 \mathrm{~g})$ was suspended in $15 \mathrm{~mL}$ of distilled water 
202 containing Pancreatin $(100 \mathrm{U} / \mathrm{mL})$. The mixture was incubated and analyzed as described above.

203 Each of the samples was measured in triplicate.

\section{3. RESULTS AND DISCUSSION}

\subsection{Selection of a fatty acid}

206 There was no visible phase separation for all three mixtures at the molten state (Fig. 1A). After

207 being placed at room temperature $\left(23^{\circ} \mathrm{C}\right)$ for $6 \mathrm{~h}$, the molten mixture of thymol and lauric acid 208 was still in a clear liquid state without having phase separation, however, the other two molten 209 mixtures (thymol / palmitic acid and thymol / stearic acid) solidified and formed a gel-like 210 mixture (Fig.1B).

211 These results are consistent with the DSC measurements. As shown in Fig. 2, the mixture of 212 lauric acid and thymol exhibited a single melting peak with a value of $30.6^{\circ} \mathrm{C}$, which is lower 213 than both that of thymol $\left(52.8^{\circ} \mathrm{C}\right)$ and lauric acid $\left(47.4^{\circ} \mathrm{C}\right)$. This suggested that the mixture of 214 lauric acid and thymol was in a eutectic solution, that is, a mixture of two or more pure 215 chemicals at certain ratios, in which the chemicals inhibit the crystallization process of one 216 another, resulting in a system having induced melting point depression (Washburn, 1924).

217 Once cooling the emulsions, thymol crystalized in irregular shapes (Fig. 3A), whereas lauric acid 218 crystalized in round shapes (Fig. 3B). The resulted mixture of the two crystalized into somewhat 219 ovular shaped particles without visible distinctions between the two individual components (Fig. $2203 \mathrm{C}$ ). This observation indicates that thymol and lauric acid co-crystalized together. Both results 221 from DSC and microscopy observation showed that thymol and lauric acid form a pair of a good 222 candidate for a formulation of antimicrobial microparticles for the following reasons. Firstly, 223 since lauric acid significantly reduced the melting point of thymol, it served as a liquid carrier for 224 thymol at room temperature for a period up to $6 \mathrm{~h}$. This property provides an excellent 
225 convenience for processing of thymol products such as in the present study. This is because

226 when at a liquid state, thymol and fatty acids can be easily mixed and better absorbed by the

227 starch granules which helps to ensure even distribution and better protection of the core

228 ingredients within the encapsulation matrix. Secondly, a combination of thymol with lauric acid

229 in one product may provide additional protective benefits to the animals. An in vitro study

230 demonstrated that lauric acid could effectively inhibit the growth of Brachyspira hyodysenteriae

231 with a MIC value less than $1.5 \mathrm{mM}$ (Vande Maele et al., 2016). Dietary fats with a considerable

232 level of lauric acid and myristic acid increased broiler growth performance that may be related to

233 lauric acid's antimicrobial properties (Zeitz et al., 2015). Most recently there was a study

234 showing that lauric acid can reduce Campylobacter spp. in broiler meat (Zeiger et al., 2017).

235 Lauric acid's ester derivatives (e.g., monolaurin) are also known for their protective biological

236 activities as antimicrobial agents (Seleem et al., 2016). The exact mechanism of lauric acid anti-

237 microbial effect is still unclear. However, it is believed that some MCFA can damage the cell

238 membrane, therefore, causing bacterial death (Desbois et al. 2010). It has been believed that the

239 amphipathic structure of MCFA allows them to cause pores with a different size in the cell

240 membrane. MCFA also could cause bacteria death by reducing enzyme function, blocking

241 nutrient absorption and producing toxic compounds for bacteria (Desbois et al. 2010). Therefore,

242 in this study lauric acid is not only a suitable carrier for thymol but also a bioactive compound

243 with antimicrobial properties.

244 3.2. Morphology of microparticles

245 The compositions of microparticles with/without alginate include $66.22 \% / 66.67 \%$ cornstarch, $24611.03 \% / 11.11 \%$ pre-gelatinized starch, 11.03\%/11.11\% thymol, 11.03\%/11.11\% lauric acid and $247 \quad 0.7 \% / 0 \%$ alginate. The average particle sizes of the microparticles were $800 \mu \mathrm{m}$ in diameter, and 
248 this was similar to the average size of $890 \mu \mathrm{m}$ for microparticles produced by Benavides et al. 249 (2016) through the method of ionic gelation of alginate. There is no difference in the average 250 particle size between the microparticles produced with or without alginate; however, the shapes 251 and surfaces of the two types of microparticles were different (Fig. 4). The microparticles with 252 alginate were mostly spherical with a relatively smooth surface, whereas those without alginate 253 had irregular shapes with rough edges and coarse surfaces.

254 Many kinds of polymers have been employed to encapsulate and deliver bioactive compounds in 255 both food and feed applications (Almeida et al., 2013; Zhang et al., 2016a; Chen et al., 2017). 256 For applications in animal feeds, it is better to use natural polymers that have been approved for 257 use in feeds. Starch is popularly used for microencapsulation because it is biodegradable, edible, 258 commonly available at low cost, nonallergic, easy to use and thermo-processable (Zhu, 2017). 259 Starch consists of both amylose and amylopectin (Tester et al., 2004; Udachan et al., 2012). Pre260 gelatinized starch has undergone processing under intense heat conditions by cooking, drying 261 and making into fine powder thus, leading to better solubility in water and being readily 262 solubilized at room temperature (Romano et al., 2018; Fiorda et al., 2015). The combined use of 263 cornstarch and pre-gelatinized starch in this study increases the water retentivity (Romano et al. 264 2018), thus promotes hydrogen bonding and the formation of the network in the encapsulation 265 matrix. As a natural polymer derived from brown seaweed, alginate is a linear and anionic 266 polysaccharide (Dragan, 2014). At room temperature, alginate is soluble in water allowing the 267 formation of gel without heating and cooling cycles, which make alginate as an attractive 268 microencapsulation material for feed applications (Benavides et al., 2016; Agüero et al., 2017). 269 The inclusion of alginate to the starch matrix improved the shape and surface properties. This 
270 could be attributed to its remarkable crosslinking capability and excellent film-forming 271 properties.

272

273

274

275

276

277

278

279

280

281

282

283 mins after they were placed in the SIF.

284

285

286

287

288

289

290

291

292

\subsection{In vitro release profiles of thymol and lauric acid from the microparticles}

As shown in Fig. 5A, both thymol and lauric acid encapsulated in the microparticles with alginate exhibited slow release profiles in the simulated gastrointestinal fluids. The cumulative release (\%) of thymol and lauric acid increased gradually to $21.2 \pm 2.3$ and $36.0 \pm 1.1$ in the SSF, $73.7 \pm 6.9$ and $36.8 \pm 0.6$ in SGF. Both thymol and lauric acid were completely released in the SIF within 240 min. However, as shown in Fig. 5B, the microparticles produced without alginate had a rapid release of thymol $(79.9 \pm 11.8 \%)$ and lauric acid $(80.8 \pm 5.9 \%)$ after incubation in the $\mathrm{SSF}$ for $2 \mathrm{~min}$. When the microparticles were placed in the SGF for $120 \mathrm{~min}$, the cumulative release rates reached $92.5 \pm 3.5 \%$ and $75.8 \pm 5.9 \%$ respectively for thymol and lauric acid. The rest of thymol and lauric acid were released from both types of microparticles in less than 40

The goal of a current delivery method is to release thymol and lauric acid at a low percentage in the mouth and stomach but have a sustained release as it passes through the intestine (Piva et al. 2007). The fast release of thymol and lauric acid in SSF from the microparticles without alginate is primarily due to the presence of alpha-amylase in the SSF, an enzyme that is known to digest starch quickly. The excellent solubility of pre-gelatinized starch could also have contributed to the fast release of the active components. The inclusion of alginate to the starch matrix markedly reduced the release rate in the SSF. This is mainly due to the existences of carboxylic groups in alginate molecules and calcium ions in the simulated digestive fluids. Calcium ions may form crosslinks between carboxylic groups in addition to hydrogen bondings, leading to enhanced 
293 networks of encapsulation matrix, therefore, retard the dissolution of starch molecules and slow

294 the release of thymol and lauric acid. The globular shaped and smooth surface of microparticles 295 with alginate would have a smaller specific surface area compared to the irregular shaped and 296 rough surface of microparticles without alginate. This may be another factor contributing to the 297 better release property of alginate containing microparticles. Notably, alginate also effectively 298 reduced the release of active components in the SGF which can be explained by the $\mathrm{pH}$ 299 sensitivity of alginate molecules. When it is under very acidic conditions (e.g., pH at stomach) 300 that are lower than its $\mathrm{pKa}$, the carboxylic groups are not ionized and stay as $\mathrm{COOH}$ resulting in 301 an insoluble structure (Agüero et al., 2017). When $\mathrm{pH}$ is close to 7 which is similar to the 302 intestinal $\mathrm{pH}$, the carboxylic groups became ionized (COO-) resulting in that the polymer chain 303 significantly expands and the hydrophilic alginate matrix enlarges (Agüero et al., 2017). In this 304 study, the results indeed demonstrated that alginate significantly decreased the release of thymol 305 and lauric acid in SGF and increased their release in the SIF. Many studies have shown that 306 alginate matrix prevented a quick release of active components in the acidic environment of the 307 stomach and allowed a prolonged release under the intestinal conditions (Zastre, 1997, Zhang et 308 al. 2016a). However, compounds that are highly soluble and have a low molecular weight cannot 309 be prevented from releasing in the mouth and stomach even though the granules matrix does not 310 erode or swell. The alginate-containing microparticles developed in this study need to be further 311 optimized to reduce the release rates in the SSF and SGF.

312 Although the release behavior of thymol and lauric acid from the microparticles provides 313 precious information, it is challenging to precisely demonstrate release behavior in pig gut 314 because of the complexity of gut physiological environments. This was supported by the study 315 indicating that the rate of release of encapsulated carvacrol in the pig stomach via in vivo studies 
316

317

318

319

320

321

322

323

324

325

326

327

328

329

330

331

332

333

334

335

336

337

338

was $25 \%$ higher than the rate obtained from in vitro studies (Zhang et al., 2016a), which may be due to the phenolic binding to other components such as fats and hydrophobic compounds present in the diet (Lallès et al., 2009). Therefore, in vivo release behavior of the microparticles has to be determined eventually in the gastrointestinal tract of pigs.

\subsection{The stability of microparticles with/without alginate during storage}

As shown in Fig. 6, thymol and lauric acid had good stabilities ( $>95 \%)$ in both types of microparticles with or without alginate after being stored at room temperature $\left(23^{\circ} \mathrm{C}\right)$ for 2 weeks. As shown in Fig. 7, thymol and lauric acid had good stabilities (>90\%) in both types of microparticles with or without alginate after being stored at $4^{\circ} \mathrm{C}$ for 12 weeks. Durante et al. (2012) showed that the encapsulation of wheat bran oil into $2 \%(\mathrm{w} / \mathrm{v})$ sodium alginate beads significantly increased the stability of wheat bran oil at $4^{\circ} \mathrm{C}$. This was also found in the research conducted by Otálora et al. (2016), that the encapsulation of betalain with calcium-alginate had good stability when stored at low relative humidity.

Stability during storage is an essential factor that should be considered for a feed additive. Feed additives have a 1-2 year shelf life under current industry practice. Our preliminary data demonstrated that the current microparticles are stable during short-term storage. However, the stability of long-term storage (e.g.1-2 year) must be further investigated. The inclusion of antioxidants in the formula may be considered to enhance the stability of encapsulated thymol and lauric acid. In conclusion, the formulation and method established in this study for the encapsulation of thymol and lauric acid in microparticles are relatively simple and can be used as a potential method to effectively deliver essential oils and MCFA to the pig intestinal tract. This unique essential oil formula will be further optimized for better-controlled release though 
339 investigating the physicochemical and molecular property of the microparticles. Retention of 340 encapsulated thymol and lauric acid during feed processing will be mimicked by the treatments 341 of steam for different time periods and validated in a real pelleting process. Further 342 investigations are needed to confirm the efficacy of the microparticles with in vivo studies.

344 Notes

345 The authors declare the following competing financial interest (s): Drs. C. Yang, S. Liu, and M. 346 Nyachoti have a patent application in process for the developed microparticles.

\section{ACKNOWLEDGMENTS}

349 This work was financially supported by the Natural Sciences and Engineering Council of Canada 350 (NSERC) CRD Grant (C. Yang, CRDPJ 503580-16), Manitoba Pork Council (C. Yang, 47370), 351 Jefo Nutrition Inc. (C. Yang, 47369), and the Start-Up Grant (C. Yang, 46561) and the Graduate 352 Enhancement of Tri-Council Stipends (GETS) program from the University of Manitoba. The 353 authors thank Natasha Brown and Bingqi Dong for their assistance in preparing the manuscript. 354 We also want to thank Philip Strange at AAFC for his help on the use of a microscope. 


\section{REFERENCES}

1. Agüero L, Zaldivar-Silva D, Peña L, Dias ML. Alginate microparticles as oral colon drug delivery device: A review. Carbohydr Polym. 2017, 168: 32-43.

2. Almeida AP, Rodríguez-Rojo S, Serra AT, Vila-Real H, Simplicio AL, Delgadilho I, da Costa SB, da Costa LB, Nogueira ID, Duarte CM. Microencapsulation of oregano essential oil in starch-based materials using supercritical fluid technology. Innov Food Sci Emerg Technol. 2013, 20: 140-145.

3. Benavides S, Cortés P, Parada J, Franco W. Development of alginate microspheres containing thyme essential oil using ionic gelation. Food Chem. 2016, 204: 77-83.

4. Brenes A, Roura E. Essential oils in poultry nutrition: Main effects and modes of action. Anim Feed Sci Tech. 2010, 158: 1-14.

5. Chen J, Wang Q, Liu CM, Gong J. Issues deserve attention in encapsulating probiotics: critical review of existing literatures. Crit Rev Food Sci Nutr. 2017, 57: 1228-1238.

6. Chitprasert P, Sutaphanit P. Holy basil (Ocimum sanctum Linn.) essential oil delivery to swine gastrointestinal tract using gelatin microcapsules coated with aluminum carboxymethyl cellulose and beeswax. J Agric Food Chem. 2014, 62: 12641-12648.

7. de Los Santos FS, Donoghue A, Venkitanarayanan K, Dirain M, Reyes-Herrera I, Blore P, Donoghue DJ. Caprylic acid supplemented in feed reduces enteric Campylobacter jejuni colonization in ten-day-old broiler chickens. Poult Sci. 2008, 87: 800-804.

8. De Smet S, Michiels J, Ovyn A, Dierick N, Laget M, Cools A, et al. Gut antibacterial effects of C7 and C9 carboxylic acids in the diet of piglets. J Anim Sci. 2016, 94: 54e7.

9. Del Nobile MA, Conte A, Incoronato AL, Panza O. Antimicrobial efficacy and release kinetics of thymol from zein films. J Food Eng. 2008, 89: 57-63. 
379 10. Desbois AP, Smith VJ. Antibacterial free fatty acids: activities, mechanisms of action and $380 \quad$ biotechnological potential. Appl Environ Microbiol. 2010, 85: 1629-1642.

381 11. Dragan ES. Design and applications of interpenetrating polymer network hydrogels. A 382 review. Chem Engin J. 2014, 243: 572-590.

383 12. Durante M, Lenucci MS, Laddomada B, Mita G, Caretto S. Effects of sodium alginate bead 384 encapsulation on the storage stability of durum wheat (Triticum durum Desf.) bran oil 385 extracted by supercritical $\mathrm{CO}_{2}$. J Agric Food Chem. 2012, 60: 10689-10695.

13. Edris AE. Pharmaceutical and therapeutic potentials of essential oils and their individual volatile constituents: a review. Phytother Res. 2007, 21: 308-323.

14. Fiorda FA, Soares Jr MS, da Silva FA, de Moura CM, Grossmann MV. Physical quality of snacks and technological properties of pre-gelatinized flours formulated with cassava starch and dehydrated cassava bagasse as a function of extrusion variables. LWT-Food Sci Technol. 2015, 62: 1112-1119.

392 15. Gonçalves ND, de Lima Pena, F, Sartoratto A, Derlamelina C, Duarte MCT, Antunes AEC, 393 Prata AS. Encapsulated thyme (Thymus vulgaris) essential oil used as a natural preservative 394 in bakery product. Food Res Int. 2017, 96: 154-160.

395 16. Gong J, Yin F, Hou Y, Yin Y. Chinese herbs as alternatives to antibiotics in feed for swine 396 and poultry production: Potential and challenges in application. Can J Anim Sci. 2014, 94: $397 \quad 223-241$.

398 17. Han YK, Hwang IH, Thacker PA. Use of a micro-encapsulated eucalyptus-medium chain 399 fatty acid product as an alternative to zinc oxide and antibiotics for weaned pigs. J Swine $400 \quad$ Health Prod. 2011, 19: 34-43. 
401 18. Hanczakowska E, Szewczyk A, Swiatkiewicz M, Okon K. Short-and medium-chain fatty 402 acids as a feed supplement for weaning and nursery pigs. Pol J Vet Sci. 2013, 16: 647-654.

403 19. Hassan YI, Lahaye L, Gong MM, Peng J, Gong J, Liu S, Gay C, Yang C. Innovative drugs, 404 chemicals, and enzymes within the animal production chain. Vet Res. 2018, 49: 71.

405

406

407

408

409

410

411

412

413

414

415

416

417

418

419

420

421

20. Hulánková R, Bořilová G. In vitro combined effect of oregano essential oil and caprylic acid against Salmonella serovars, Escherichia coli O157: H7, Staphylococcus aureus and Listeria monocytogenes. Acta Vet Brno. 2011, 80: 343-348.

21. Lallès JP, Bosi P, Janczyk P, Koopmans SJ, Torrallardona D. Impact of bioactive substances on the gastrointestinal tract and performance of weaned piglets: a review. Animal. 2009, 3: $1625-1643$.

22. Li SY, Ru YJ, Liu M, Xu B, Péron A, Shi XG. The effect of essential oils on performance, immunity and gut microbial population in weaner pigs. Livest Sci. 2012, 145: 119-123.

23. Looft T, Johnson TA, Allen HK, Bayles DO, Alt DP, Stedtfeld RD, Sul WJ, Stedtfeld TM, Chai B, Cole JR, Hashsham SA, Tiedje JM, Stanton TB. In-feed antibiotic effects on the swine intestinal microbiome. Proc Natl Acad Sci USA. 2012, 109: 1691-6.

24. Ma YH, Wang Q, Gong J and Wu XY. Formulation of granules for site-specific delivery of an antimicrobial essential oil to the animal intestinal tract. J Pharm Sci. 2016, 105: 11241133.

25. Messens W, Goris J, Dierick N, Herman L and Heyndrickx M. Inhibition of Salmonella typhimurium by medium-chain fatty acids in an in vitro simulation of the porcine cecum. Vet Microbiol. 2010, 141:73-80. 
422 26. Michiels J, Missotten J, Dierick N, Fremaut D, Maene P, ade Smet S. In vitro degradation 423 and in vivo passage kinetics of carvacrol, thymol, eugenol and trans-cinnamaldehyde along 424 the gastrointestinal tract of piglets. J Sci Food Agric. 2008, 88: 2371-2381.

425 27. Minekus M, Alminger M, Alvito P, Ballance S, Bohn TO, Bourlieu C, Carriere F, Boutrou R, 426 Corredig M, Dupont D, Dufour C, Egger L, Golding M, Karakaya S, Kirkhus B, Le Feunteun 427 S, Lesmes U, Macierzanka A, Mackie A, Marze S, McClements DJ, Ménard O, Recio I, 428 Santos CN, Singh RP, Vegarud GE, Wickham MS, Weitschies W, Brodkorb A. A 429 standardised static in vitro digestion method suitable for food-an international consensus. $430 \quad$ Food Funct. 2014, 5: 1113-1124.

431 28. Omonijo FA, Ni L, Gong J, Wang Q, Lahaye L, Yang C. Essential oils as alternatives to 432 antibiotics in swine production. Anim Nutr. 2018, 4: 126-136.

433 29. Otálora MC, Carriazo JG, Iturriaga L, Osorio C, Nazareno MA. Encapsulating betalains from 434 Opuntia ficus-indica fruits by ionic gelation: Pigment chemical stability during storage of 435 beads. Food Chem. 2016, 202: 373-382.

436 30. Pitigraisorn P, Srichaisupakit K, Wongpadungkiat N, Wongsasulak S. Encapsulation of 437 Lactobacillus acidophilus in moist-heat-resistant multilayered microcapsules. J Food Engin. $438 \quad 2017,192: 11-18$.

439 31. Piva A, Pizzamiglio V, Morlacchini M, Tedeschi M, Piva G. Lipid microencapsulation 440 allows slow release of organic acids and natural identical flavors along the swine intestine. J $441 \quad$ Anim Sci. 2007, 85: 486-493.

442 32. Puvaca N, Stanacev V, Glamocic D, Levicc J, Peric L, Stanacev V, Milic D. Beneficial 443 effects of phytoadditives in broiler nutrition. World's Poult Sci J. 2013, 69: 27-34. 
444 33. Rassu G, Nieddu M, Bosi P, Trevisi P, Colombo M, Priori D, Manconi P, Giunchedi P, 445 Gavini E, Boatto G. Encapsulation and modified-release of thymol from oral microparticles 446 as adjuvant or substitute to current medications. Phytomed. 2014, 21: 1627-1632.

447 34. Romano N, Kanmani N, Ebrahimi M, Chong CM, Teh JC, Hoseinifar SH, Amin SN, 448 Kamarudin MS, Kumar V. Combination of dietary pre-gelatinized starch and 449 isomaltooligosaccharides improved pellet characteristics, subsequent feeding efficiencies and 450 physiological status in African catfish, Clarias gariepinus, juveniles. Aquaculture. 2018, 484: 293-302.

452

35. Rossi R, Pastorelli G, Cannata S, Corino C. Recent advances in the use of fatty acids as supplements in pig diets: a review. Anim Feed Sci Technol. 2010, 162: 1-11.

36. Seleem D, Chen E, Benso B, Pardi V, Murata RM. In vitro evaluation of antifungal activity 455 of monolaurin against Candida albicans biofilms. PeerJ. 2016, 4: e2148.

37. Si W, Gong J, Chanas C, Cui S, Yu H, Caballero C, Friendship RM. In vitro assessment of 457 antimicrobial activity of carvacrol, thymol and cinnamaldehyde towards Salmonella serotype Typhimurium DT104: Effects of pig diets and emulsification in hydrocolloids. J Appl Microbiol. 2006a, 101: 1282-1291.

38. Si W, Gong J, Tsao R, Zhou T, Yu H, Poppe C, Johnson R, Du Z. Antimicrobial activity of essential oils and structurally related synthetic food additives towards selected pathogenic and beneficial gut bacteria. J Appl Microbiol. 2006b, 100: 296-305.

39. Tester RF, Karkalas J, Qi X. Starch—composition, fine structure and architecture. J Cereal Sci. 2004, 39: 151-165. bicolor L. Moench) starch. Int Food Res J. 2012, 19: 315-319. 
467 41. Van Immerseel F, De Buck J, Boyen F, Bohez L, Pasmans F, Volf J, Sevcik M, Rychlik I, 468 Haesebrouck F and Ducatelle R. Medium-chain fatty acids decrease colonization and 469 invasion through hilA suppression shortly after infection of chickens with Salmonella 470 enterica serovar Enteritidis. Appl Environ Microbiol. 2004, 70:3582-3587.

471 42. Vande Maele L, Heyndrickx M, Maes D, De Pauw N, Mahu M, Verlinden M, Haesebrouck

472 F, Martel A, Pasmans F, Boyen F. In vitro susceptibility of Brachyspira hyodysebteruae to 473 organic acids and essential oil components. J Vet Med Sci. 2016, 78: 325-328.

474 43. Washburn EW. Melting and freezing points of pure substances and of eutectic mixtures. Ind. $475 \quad$ Eng. Chem. 1924, 16: 275-275.

476 44. Yang CB, Chowdhury MAK, Hou Y, Gong J. Phytogenic compounds as alternatives to in477 feed antibiotics: potentials and challenges in application. Pathogens. 2015, 4: 137-156.

478 45. Zastre JA. Evaluation of calcium alginate beads as a prolonged release delivery system for an 479 orally active iron chelator. PhD thesis at the University of Manitoba.1997.

480 46. Zeiger K, Popp J, Becker A, Hankel J, Visscher C, Klein G, Meemken D. Lauric acid as feed 481 additive - An approach to reducing Campylobacter spp. in broiler meat. PLoS One. 2017, 12: $482 \quad \mathrm{e} 0175693$.

483 47. Zeitz JO, Fennhoff J, Kluge H, Stangl GI, Eder K. Effects of dietary fats rich in lauric and 484 myristic acid on performance, intestinal morphology, gut microbes, and meat quality in 485 broilers. Poult Sci. 2015, 94: 2404-2413.

486 48. Zentek J, Buchheit-Renko S, Ferrara F, Vahjen W, Van Kessel A, Pieper R. Nutritional and 487 physiological role of medium-chain triglycerides and medium-chain fatty acids in piglets. 488 Anim Health Res Rev. 2011, 12: 83-93. 
489 49. Zentek J, Buchheit-Renko S, Männer K, Pieper R, Vahjen W. Intestinal concentrations of 490 free and encapsulated dietary medium-chain fatty acids and effects on gastric microbial 491 ecology and bacterial metabolic products in the digestive tract of piglets. Arch Anim Nutr. $492 \quad 2012,66: 14-26$.

493 50. Zentek J, Ferrara F, Pieper R, Tedin L, Meyer W, Vahjen W. Effects of dietary combinations 494 of organic acids and medium chain fatty acids on the gastrointestinal microbial ecology and 495 bacterial metabolites in the digestive tract of weaning piglets. J Anim Sci 2013, 91: 3200$496 \quad 3210$.

497 51. Zhang Y, Wang QC, Yu H, Zhu J, de Lange K, Yin Y, Wang Q, Gong J. Evaluation of 498 alginate-whey protein microcapsules for intestinal delivery of lipophilic compounds in pigs. J $499 \quad$ Sci Food Agric. 2016a, 96: 2674-2681.

500 52. Zhang Z, Zhang R, Zou L, McClements DJ. Protein encapsulation in alginate hydrogel 501 beads: Effect of $\mathrm{pH}$ on microgel stability, protein retention and protein release. Food $502 \quad$ Hydrocol. 2016b, 58: 308-315.

503 53. Zhu F. Encapsulation and delivery of food ingredients using starch-based systems. Food $504 \quad$ Chem. 2017, 229: 542-552. 


\section{Figure legends}

506

507

508

509

510

511

512 513 to $80^{\circ} \mathrm{C}$.

514

515

516

517

518

519

520

521

522

523

524

525

526

Fig. 1. A) Pictures showing the molten mixture of thymol and fatty acids at 0 min at room temperature $\left(23^{\circ} \mathrm{C}\right)$. B) Pictures showing the molten mixture of thymol and fatty acids at $6 \mathrm{~h}$ at room temperature $\left(23^{\circ} \mathrm{C}\right)$. FA1 - mixture of thymol and lauric acid, FA2 - mixture of thymol and palmitic acid; FA3 - mixture of thymol and stearic acid.

Fig. 2. Differential scanning calorimetry (DSC) of (A)Thymol, (B) Lauric acid, and (C) Mixture of thymol and lauric acid (50: 50wt\%). The second run with heating rate $10{ }^{\circ} \mathrm{C} / \mathrm{min}$ from $-10^{\circ} \mathrm{C}$

Fig. 3. Morphology of crystals of thymol (A) and lauric acid (B) and a mixture of thymol and lauric acid (C) after crystallization. The measuring bar in the pictures were $1 \mu \mathrm{m}$.

Fig. 4. Morphology and surface diagram of the microparticles of lauric acid and thymol with and without $2 \%$ alginate observed with a light microscope. (A) Morphology of microparticles with alginate; (B) Morphology of microparticles without alginate; (C) Surface diagram of microparticles with alginate and (D) Surface diagram of microparticles without $2 \%$ alginate.

Fig. 5. In vitro release profile of thymol and lauric acid from the microparticles with (A) and without (B) alginate using simulated fluids (SSF - simulated salivary fluid, SGF - simulated gastric fluid and SIF - simulated intestinal fluid). (Mean $\pm \mathrm{SD}, \mathrm{n}=4$ ). 
527 Fig. 6. Stability of the microparticles of: (A) thymol in the microparticles with alginate, (B)

528 lauric acid in the microparticles with alginate, (C) thymol in the microparticles without alginate

529 and (D) lauric acid in the microparticles without alginate. Samples were stored at room

530 temperature $\left(23^{\circ} \mathrm{C}\right)$ for 2 weeks. (Mean $\left.\pm \mathrm{SD}, \mathrm{n}=4\right)$.

531 Fig. 7. Stability of the microparticles of thymol and lauric acid with (A) and without (B) alginate

532 stored at $4^{\circ} \mathrm{C}$ for 12 weeks. (Mean $\pm \mathrm{SD}, \mathrm{n}=4$ ).

533

534

535

536

537

538

539 
541
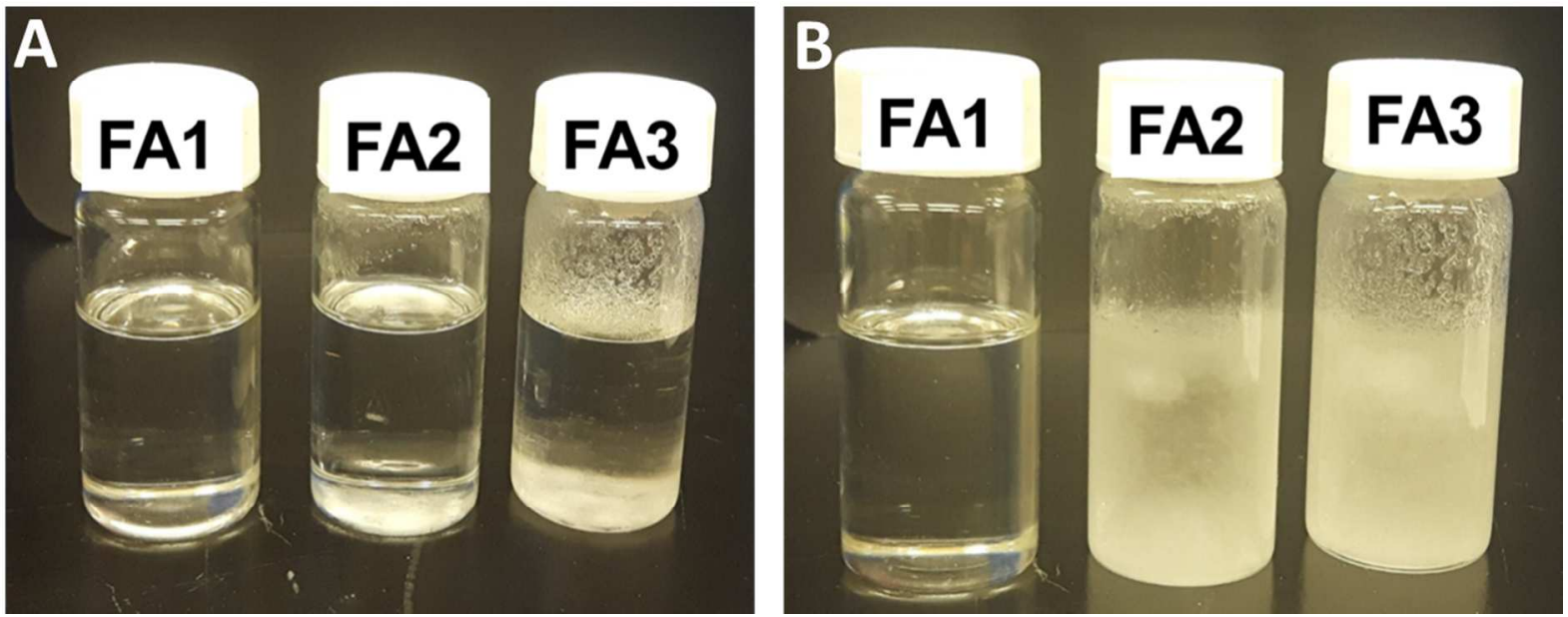
554

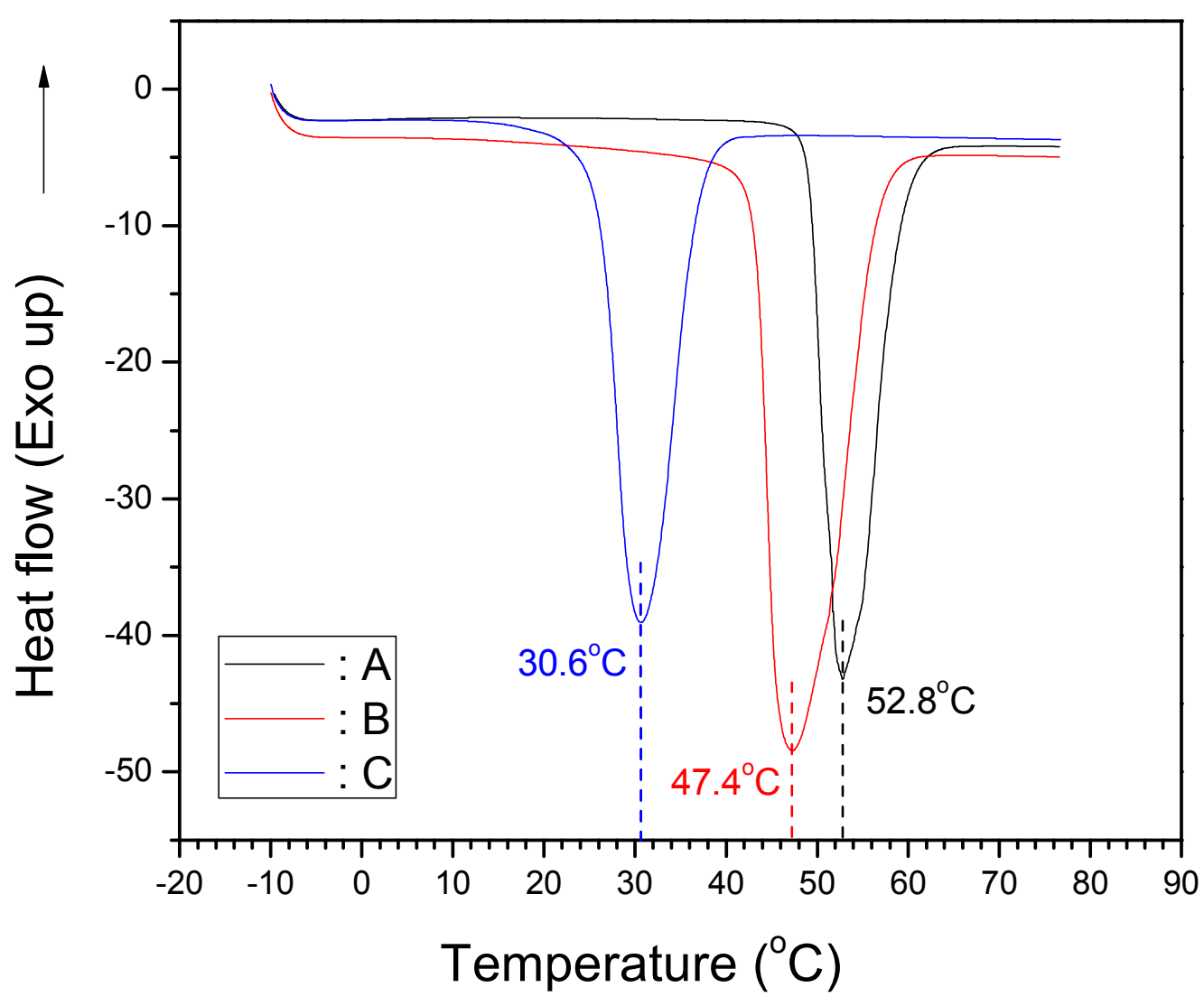

555

556

557

558

559

560

561

562 
563 Fig. 3. Omonijo et al. (2018)

564

565
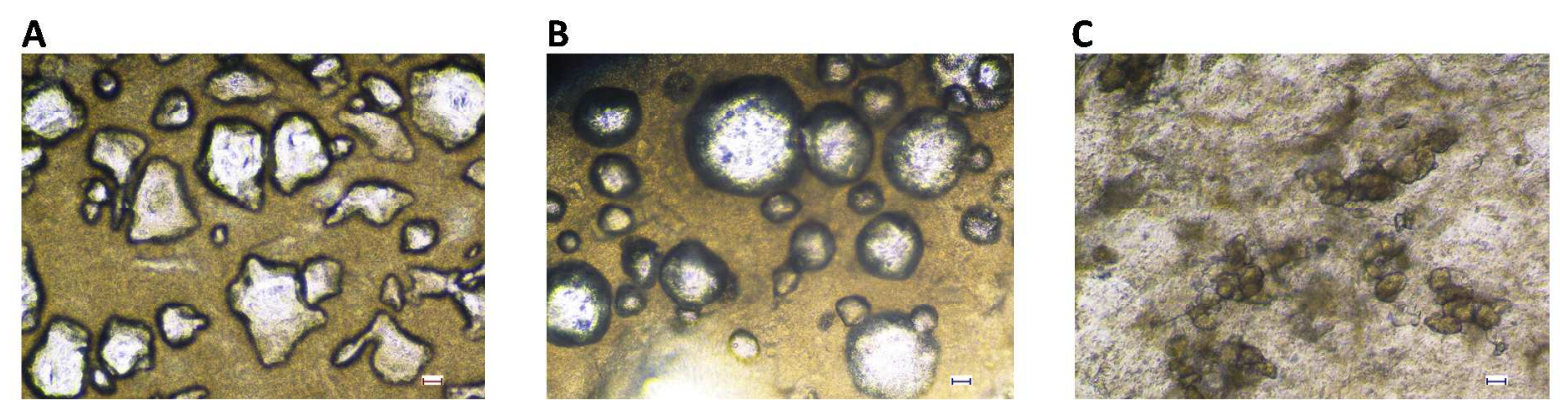

566

567

568 
570

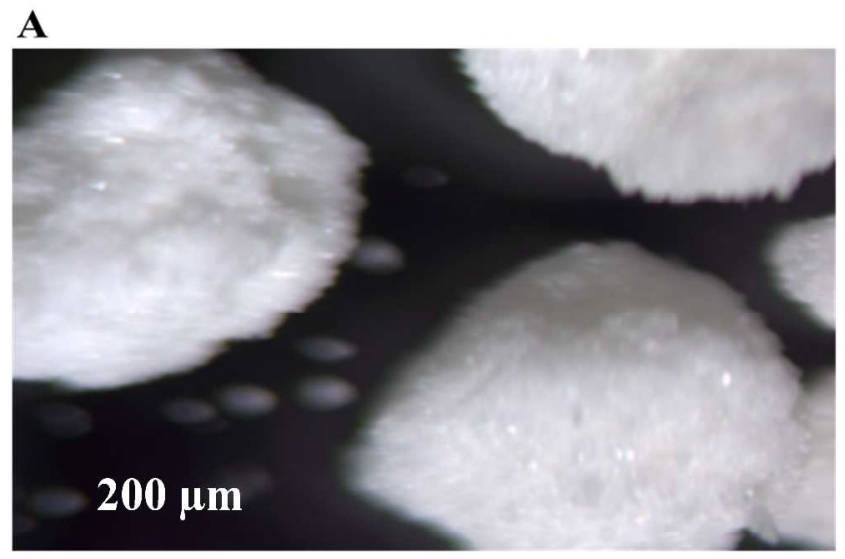

B
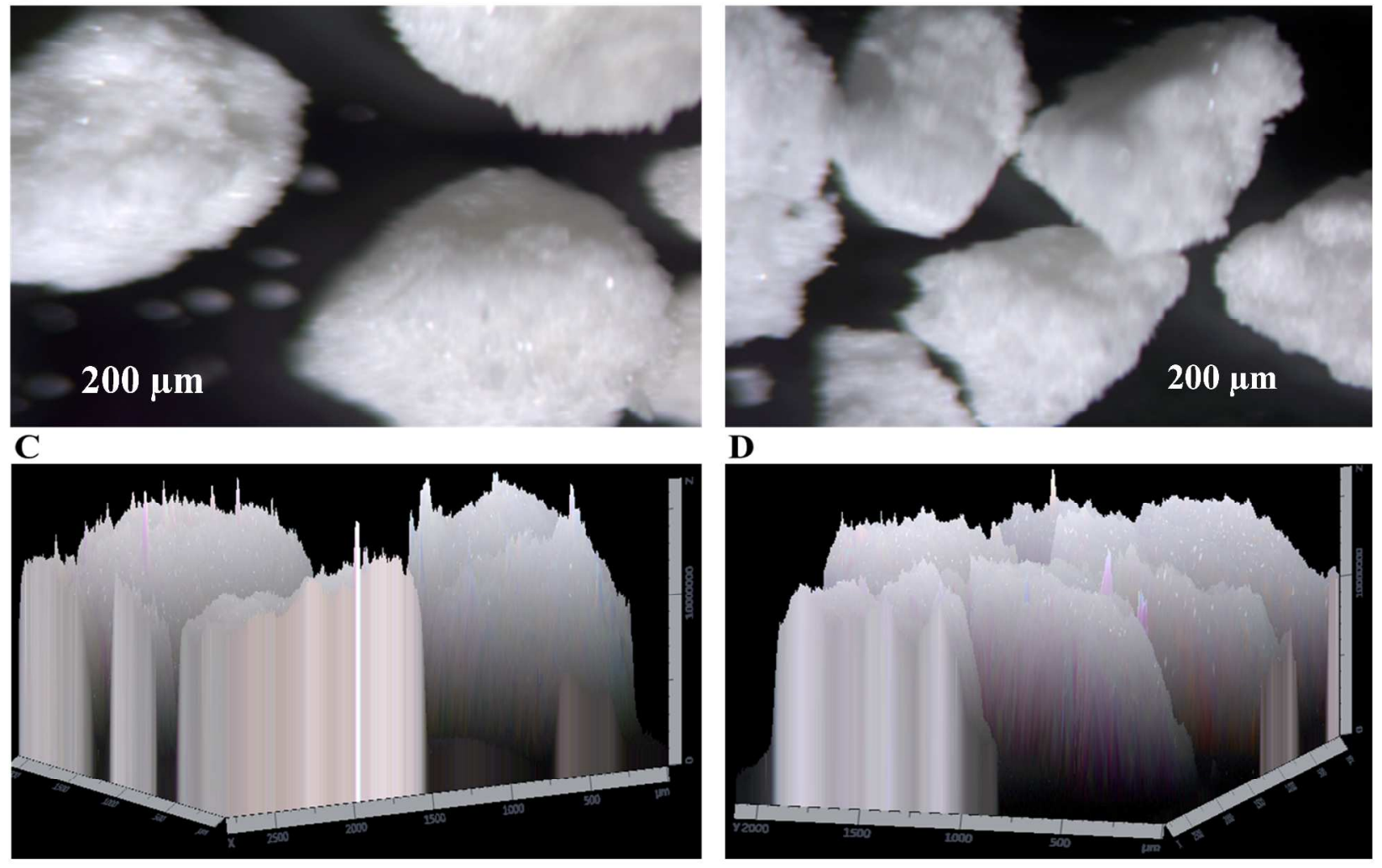

571 
A

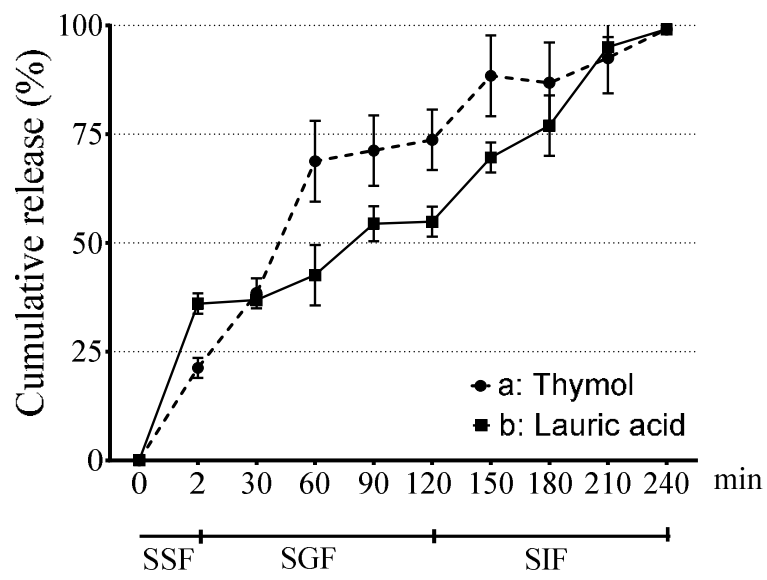

B

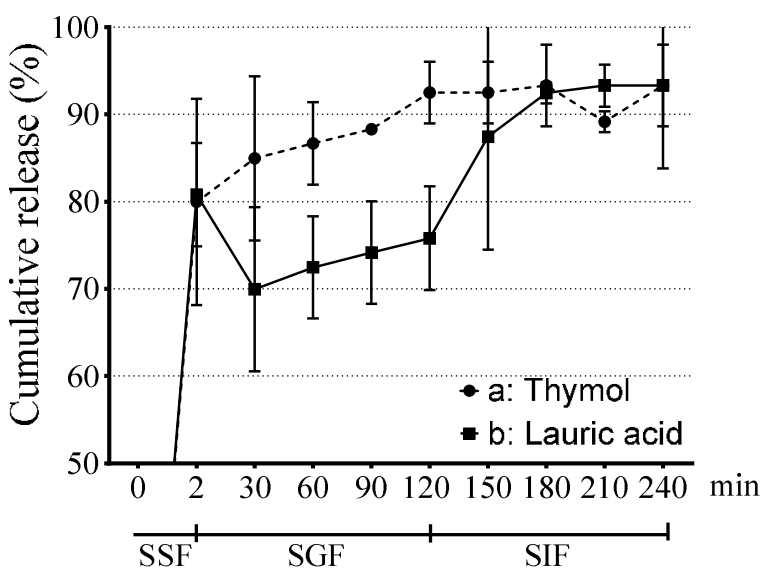


A: Microparticles with $2 \%$ alginate solution: Thymol

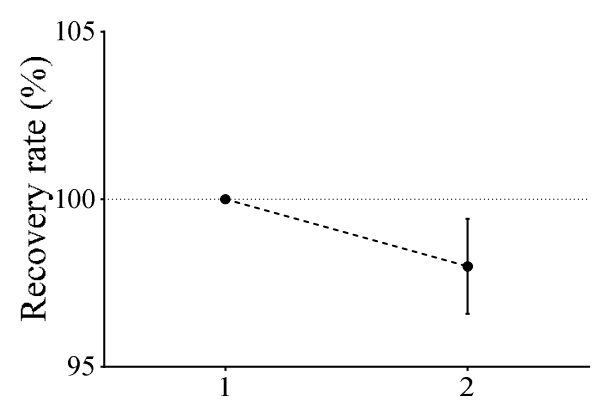

Storage period (weeks)

C: Microparticles without $2 \%$ alginate solution: Thymol

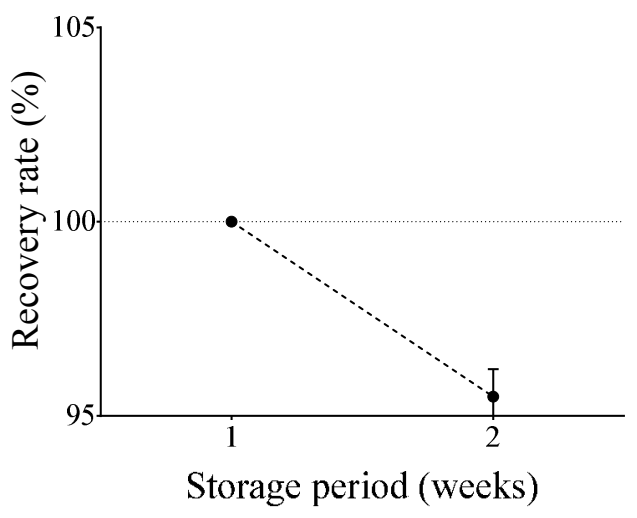

B: Microparticles with $2 \%$ alginate solution: Lauric acid

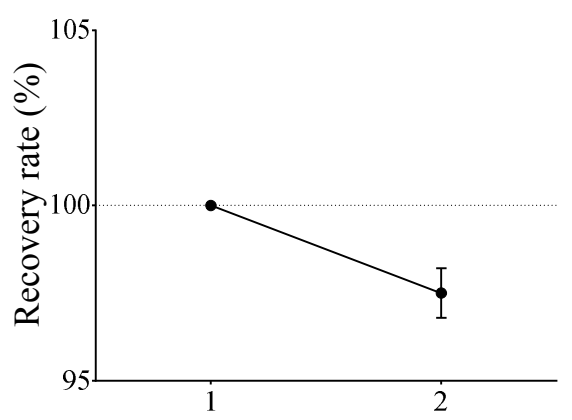

Storage period (weeks)

D: Microparticles without $2 \%$ alginate solution: Lauric acid

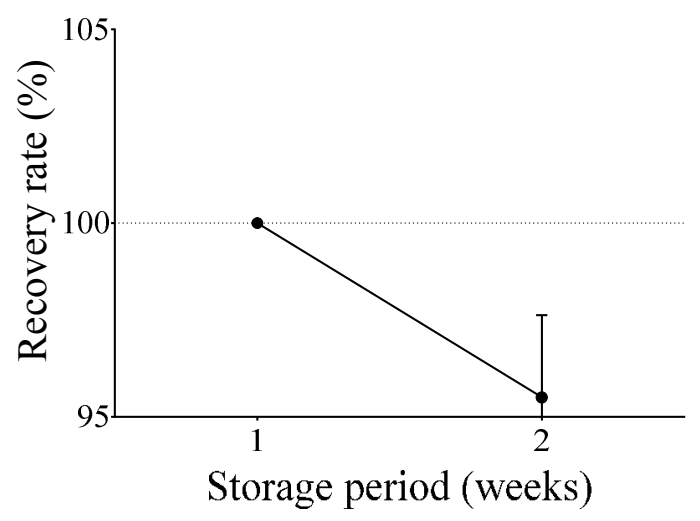

598

599

600

601

602

603

604

605 


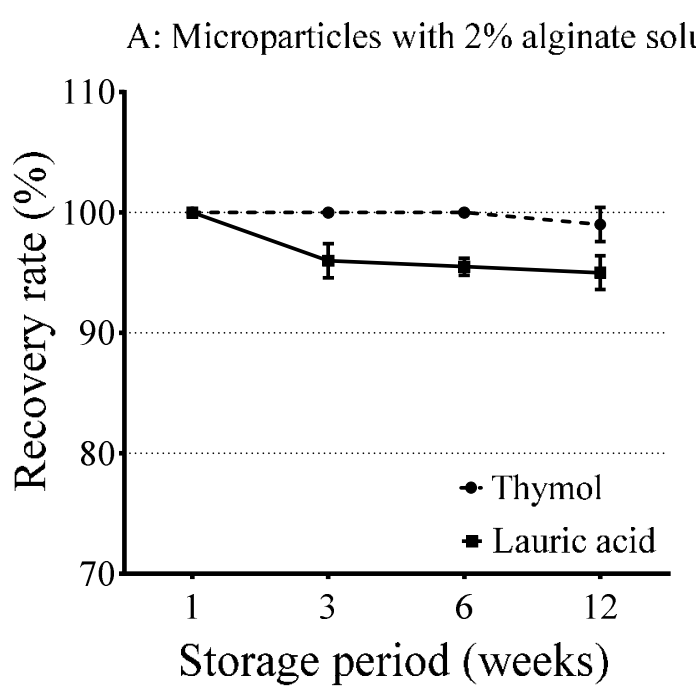

608

609

610

611

612

613

614

615

616

617

618

619

620

621 
622 TOC Graphic

\section{Step 1}

Molten mixture of thymol and lauric acid

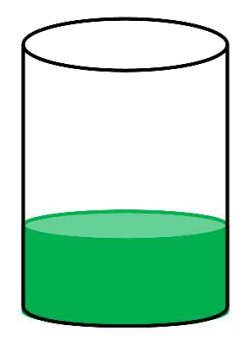

\section{Step 2}

Mix thymol/lauric acid with starch and alginate solution

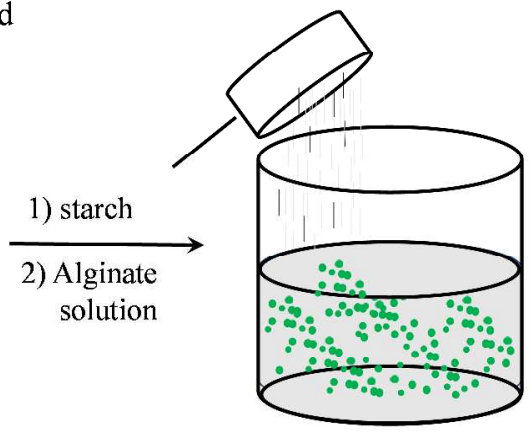

\section{Step 3}

Solidify

in an ice water bath

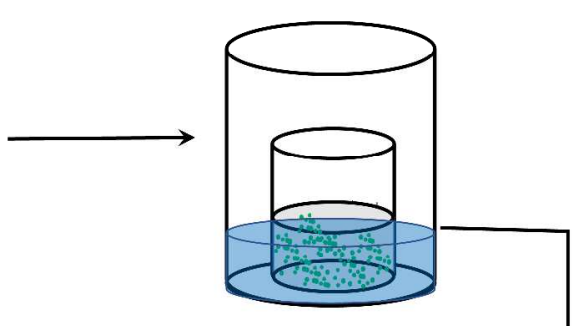

Step 4

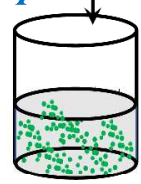

Final granules
Step 5

Grind with a granulator 